\title{
Mathematical support to make managerial decisions in the socio-economic systems of public transport enterprises
}

\author{
Alexey Shtepa ${ }^{1 *}$, Vladimir Belokurov ${ }^{1}$, and Eduard Busarin ${ }^{1}$ \\ ${ }^{1}$ Voronezh State University of Forestry and Technologies named after G.F. Morozov, 8, Timiryazeva \\ st., Voronezh, 394087, Russian Federation
}

\begin{abstract}
The structure of the management system of a public transport enterprise is determined by the services of different functional load. Such a structure includes operational and technical and economic blocks. They can function effectively only on the basis of fast and correct managerial decisions concerning the structure of the management system of a public transport enterprise. The relevance of making thoughtful and wellgrounded management decisions is dictated by the requirements to take into consideration many both macro- and microeconomic factors. In this regard, the introduction of modern management methods makes it possible to implement the principle «What to do in order to ...». The article is devoted to the mathematical modeling of the processes of a public transport enterprise to support management decisions in the field of effective enterprise planning. Such tasks can be implemented only with a systematic approach to the economic activity of a public transport enterprise and modeling both individual subsystems and the development of the enterprise system as a whole. The solution of the problems posed is proposed on the basis of the group arguments consideration method.
\end{abstract}

Taking the system of a public transport enterprise as an element of the regional economy and applying a systematic approach, there can be distinguished four main subsystems that affect the functionality of the transport enterprise system: social, economic, technological and natural ones. Thus, dividing the social and economic systems there can noted not only industrial relations, but also the relationship between the transport company and the consumers (passengers).

The sustainable development of the system of a public transport enterprise is ensured by the dynamic balance of subsystems, which is disrupted during the stagnation period, because these systems guarantee the socio-economic well-being of the city's population. Drawing a parallel to these systems with the human cardiovascular system, the systems of a public transport enterprise can be compared with arteries, which indicates the importance of effective management of this one of the most important elements of modern urban agglomerations. Methods designed to improve management, such as management variability and adaptability to different models in case of economic stagnation, provide

*Corresponding author: alexei_shtepa@mail.ru 
progressive economic development, which is especially important in relation to a transport enterprise. For such enterprises, these tasks come to increasing revenue and reducing direct and indirect costs $[1,11]$.

In the system of a transport enterprise, there can be distinguished the input parameters $X=\left(x_{1}, x_{2}, \ldots, x_{m}\right)^{T}$, which include both macro- and microeconomic characteristics of the system of a transport enterprise, and the parameters of the output flow $Y=\left(y_{1}, y_{2}, \ldots, y_{n}\right)^{T}-$ indicator of the studied process. Management of the subset $X$ is possible by highlighting the parameters of the system $x_{i}$. These parameters are the management ones. If they are ineffective, they can be replaced. The time period $T_{0}$ characterizes the minimum time period required to monitor the process under study, which is necessary to identify the process model. It is determined by the process nature, the type of the models class and the criteria used to select a process model. When the time $T_{0}$ is reached, the structural identification of the studied process of the public transport enterprise system is studied; its result shall be to obtain a model of the studied process $y_{i}$. Using the $y_{i}$ model, you can make an epigmatic forecast for a given period. The success of research on the structural identification of the process under study determines the values of the maximum error $\varepsilon_{i}$ of the model $\Delta y_{\text {ierr. }}$.

If inequation ( $\Delta y_{\text {ierr. }} \leq \varepsilon_{i}$ ) is successful, the model is used to optimize the process under study, and the optimization results are transmitted to the module to form and make management $v_{i}$. The selected management solutions $v_{i}$ are used to plan the sustainable development of a transport enterprise.

During the further economic development of the system of a public transport enterprise the adopted management decisions provide the possibility to change the initial model of the process under study, which is controlled according to the model of the error of the epignant forecast $\Delta y_{\text {ierr. }} \leq \varepsilon_{i}$ obtained at the identification stage. If $\Delta y_{i \text { err. }} \geq \varepsilon_{i}$, the structural identification of the objective function is performed.

Thus, the sustainable development of the system of a public transport enterprise is achieved by the use of effective management methods with modern mathematical methods, methods to analyse and plan the socio-economic processes. Modeling of transport logistics includes identifying certain socio-economic trends in the system of a public transport enterprise and improving its functioning $[2,9]$. These tasks can be solved by:

- determination of logistic processes, which allows to determine the direction of the public transport enterprise development. At the same time, it is necessary to divide the final goal into several local subgoals, including the accompanying socio-economic processes of the public transport enterprise system, which is not always possible by means of mathematical formalization. Self-organisation of the system with the help of management decisions made to optimize production is also impossible.

- probabilistic-adaptive approach, which ensures implementation of all the determination possibilities and at the same time allows to determine the aspects due to which the uncertainty factor of the influence of external parameters on the public transport enterprise system is reduced. Taking into account the fact that there is significant uncertainty in the socio-economic development of a public transport enterprise and the small informational sophistication of monitoring the public transport enterprise systems, dynamic predictive models based on the theory of self-organization and a probabilisticadaptive approach should be used to model logistic processes $[2,8]$.

The tasks presented above can be solved by the use of the group method of data handling (GMDH) [2,10]. Let $W$ be a set of models of class $S, K R$ be an external 
criterion to assess the quality of a model $w$ from a set $W$. Taking this into account, the structural definition based on samples of observations can be represented as

$$
w^{*}=\arg \underset{w \in W}{\min } K R(w),
$$

i.e. problem (1) is a discrete programming one. Its feature is the presence of an additional problem to estimate the parameters $w$ by the minimum of some internal criterion that does not coincide with $K R$ for each model $w \in W$.

Taking into account the close interconnection of the macro- and microeconomic development of the public transport enterprise system in the conditions of the economy, it is proposed to use the differential class of models forecast the economic activity of the public transport enterprise of the form

$$
\frac{\partial Y}{\partial t}=\sum_{i=1}^{n} a_{i} d_{i}+\sum_{j=n+1}^{2 n} a_{j} d_{j-n}^{2}+\sum_{k=2 n+1}^{2 n+\frac{n !}{2 !(n-2) !}} a_{k} \sum_{m=1}^{n-1} \sum_{p=m+1}^{n} d_{m} d_{p}+a_{0},
$$

where $\mathrm{Y}$ - the parameter of the public transport enterprise system under study (usually $\mathrm{Y}$ - service revenue), $\mathrm{d}=\partial \mathrm{x}_{\mathrm{i}}^{\mathrm{t}-\mathrm{z}} / \partial \mathrm{t}, x_{1}, x_{2}, \ldots$ - the parameters of the public transport enterprise system, $\mathrm{t}$ - time, $z$ - delay period $(z=0,1,2), a_{1}-a_{n}$ - coefficient of the parameters of the public transport enterprise system, $a_{0}$ - free term.

The internal processes of the public transport enterprise system, as a rule, are unique for each specific system [2], for example, the cost of travel, fuel and others, which allows to use equations with a polynomial dependence to identify them

$$
\mathrm{w}_{\mathrm{e}}=\sum_{\mathrm{i}=1}^{\mathrm{n}} \mathrm{a}_{\mathrm{i}} w_{\mathrm{i}}+\sum_{\mathrm{j}=\mathrm{n}+1}^{2 \mathrm{n}} \mathrm{a}_{\mathrm{j}} w_{\mathrm{j}-\mathrm{n}}^{2}+\sum_{\mathrm{k}=2 \mathrm{n}+1}^{2 \mathrm{n}+\frac{\mathrm{n} !}{2 !(\mathrm{n}-2) !}} \mathrm{a}_{\mathrm{k}} \sum_{\mathrm{m}=1 \mathrm{p}=m+1}^{\mathrm{n}-1} \sum_{m}^{\mathrm{n}} \mathrm{w}_{\mathrm{p}}+\mathrm{a}_{0},
$$

where $n$-the number of independent internal parameters $(S)$ of the specified system.

Representing the models of the public transport enterprise system and socio-economic processes in them as a system, we obtain

$$
\left\{\begin{array}{l}
\frac{\partial Y}{\partial t}=\sum_{i=1}^{n} a_{i} d_{i}+\sum_{j=n+1}^{2 n} a_{j} d_{j-n}^{2}+\sum_{k=2 n+1}^{2 n+\frac{n !}{2 !(n-2) !}} a_{k} \sum_{m=1}^{n-1} \sum_{p=m+1}^{n} d_{m} d_{p}+a_{0} \\
w_{1}=\sum_{i=1}^{n} a_{i} w_{i}+\sum_{j=n+1}^{2 n} a_{j} w_{j-n}^{2}+\sum_{k=2 n+1}^{2 n+(n-2) !} a_{k} \sum_{m=1}^{n-1} \sum_{p=m+1}^{n} w_{m} w_{p}+a_{0} \\
w_{e}=\sum_{i=1}^{n} a_{i} w_{i}+\sum_{j=n+1}^{2 n} a_{j} w_{j-n}^{2}+\sum_{k=2 n+1}^{2 n+\frac{n !}{2 !(n-2) !}} a_{k} \sum_{m=1}^{n-1} \sum_{p=m+1}^{n} w_{m} w_{p}+a_{0}
\end{array}\right.
$$

where $\mathrm{w}_{1}, \ldots, \mathrm{w}_{\mathrm{e}}-$ the systemically important parameters of the public transport enterprise system.

The successful study on the structural identification of the process under study is closely related to the choice of one or another external criterion to select models, as well as the order of application of external criteria in case of the multi-criteria choice of models.

As a rule, to ensure the success of studies on the structural identification of the process under study, a multi-criteria choice of the best model is used, where the following external criteria are used [2-4]: 
1. Unbiasedness criterion (minimum bias)

$$
\mathrm{KR}_{\text {bias. }}=\left\|\mathrm{m}_{\mathrm{p}_{1}}-\mathrm{m}_{\mathrm{p}_{2}}\right\| \sqrt{\mathrm{a}^{2}+\mathrm{b}^{2}}
$$

where $\mathrm{m}_{\mathrm{p}_{1}}$ and $\mathrm{m}_{\mathrm{p} 2}$ - the models, obtained according to samples $\mathrm{p}_{1}$ and $\mathrm{p}_{2}$.

2. Convergence criterion [4]

$$
\mathrm{KR}_{\text {conv. }}=\|\mathrm{u}-\mathrm{m}\|
$$

where $\mathrm{u}$ and $\mathrm{m}$ - the real and supposed output parameter values.

3. Planning accuracy criterion [3-5].

$$
\mathrm{KR}_{\text {prec. }}=\left\|\mathrm{m}_{\Omega_{\mathrm{p}_{3}}}-\mathrm{u}\right\| \text {, }
$$

where $\mathrm{m}_{\Omega \mathrm{p}_{3}}$ - the value of the investigated parameter according to sample $n_{3}$, obtained with the help of the structure assessed according to sample $\Omega$.

The adequacy of the resulting model is checked on the results of the forecast for the period $2 T$, where $T$ is the forecast time for the consistency of the process under study $\left(\mathrm{KR}_{\text {consi. }}\right)$. If it is observed, then we can talk about its security for the period $T$.

Consequently, the model of the studied process of the system of a public transport enterprise is sought in the space of 3-4 criteria (unbiasedness $\left(\mathrm{KR}_{\text {bias. }}\right)$, convergence $\left(\mathrm{KR}_{\text {conv. }}\right)$, epignant forecast $\left(\mathrm{KR}_{\text {prec. }}\right)$ and the criterion of consistency $\left.\left(\mathrm{KR}_{\text {consi. }}\right)\right)$.

The considered features to manage the system of a public transport enterprise, as well as modern technologies to determine management methods based on the theory of selforganization, made it possible to develop a methodology to obtain models of processes of the public transport enterprise system, which includes $[2,11]$ :

- analysis of input and output parameters;

- structural identification of the process under study;

- substantiation of the base class of models, taking into account the free decisionmaking of the predictive orientation of models;

- the choice of the basis to determine the models and the basis for the order of their use; creation of various model structures in the selected base class;

- estimation of the created structures parameters and formation of set $W$;

- determining the most suitable process model.

An optimal model:

- has minimum selection criteria;

- has been checked for adequacy;

- includes optimal parameters of the enterprise in the medium and long term;

- provides control of the alleged and actual aspects of the public transport enterprise system;

- ensures sustainable development of a public transport enterprise based on the operation of a permanent mathematical model of the processes of the enterprise system.

In conclusion it can be noted that there have been proposed basic classes of models that reflect the features of the competitive market for passenger transportation, which allows to obtain predictive models that ensure effective management of the system of a public transport enterprise, and an original method of structural identification of models of processes of the public transport enterprise system has been developed on the basis of a combinatorial algorithm of the group method of data handling. Taking into account the independence of the influencing factors and allowing to obtain management models for effective management of the system of a public transport enterprise in a competitive market in a stagnant economy [6-8]. 


\section{References}

1. A. Shevtsova, A.N. Novikov, S.V. Eremin, Application of Fuzzy Situational Networks in Decision Support Systems in the Transport Industry, IOP Conference Series: Earth and Environmental Science, 666 (3), 032015 (2021)

2. A.A. Shtepa, V.P. Belokurov, Making of effective management decisions to implement a systematic approach in monitoring the functioning of public transport enterprises, Information technology and innovation in transport: materials of the 6th International scientific and practical conference, pp. 68-75 (2020)

3. A. G Ivakhnenko, Long-term forecasting and management of complex systems, Kiew: Tekhnika, P. 312 (1975).

4. O.N. Dikareva, Information technologies to optimise the economic activity of an enterprise, Control systems and information technology, 1,2 (39), pp. 226-229 (2010).

5. O.V. Isaev, V.S. Starodubtsev, A.S. Dubrovin, A.S. Kravchenko, Estimation of the boundaries of the region of stable functioning of elements of special-purpose information systems characteristic, Journal of Physics: Conference Series. 12017 (2019).

6. R.G. Shkhacheva, V.S. Starodubtsev, Business process management in the construction industry, Natural and technical sciences, 2 (52), pp. 401-405 (2011).

7. V.P. Belokurov, R.A. Spodarev, R., S.V. Belokurov, Determining passenger traffic as important factor in urban public transport system, Transportation Research Procedia, 50, pp. 52-58 (2020)

8. V.P. Belokurov, S.V. Belokurov, R.A. Korablev, A.A. Shtepa, Models of expert assessments and their study in problems of choice and decision-making in management of motor transport processes, Journal of Physics: Conference Series, 1015 (3), 032132 (2018)

9. V.S. Starodubtsev, Y.N. Astashov, Probability-adaptive modeling of transport logistics, Modeling of systems and processes, 8 (4), pp. 73-77 (2015).

10. V.S. Starodubtsev, E.S. Sotnikova, Identification of models in the method of group accounting of arguments, Modeling of systems and processes, 1, pp. 58-64. (2013).

11. V.S. Starodubtsev, A.A. Shtepa, V.P. Belokurov, Probabilistic-adaptive modeling of socio-economic systems of public transport enterprises, The world of transport and technological machines, 2 (69), - pp. 116-123 (2020). 